\title{
The Evaluation of the Effectiveness of the Laboratory Centers of the Technical and Vocational Secondary Schools in Athens, Greece
}

\author{
Vasiliki Brinia (Corresponding Author) \\ Teacher Education Program, Athens University of Economics \& Business \\ 76 Patision, Athens, Attica 10434, Greece \\ E-mail: vbrinia@aueb.gr
}

Georgios Manioudakis

School of Humanities, Hellenic Open University

18 Aristotelous, Patra, Ahaia 26335, Greece

E-mail: g_manioudakis@yahoo.gr

Received: April 19, 2018 Accepted: May 21, $2018 \quad$ Published: May 23, 2018

doi: 10.5296/hrr.v2i1.13186 URL: https://doi.org/10.5296/hrr.v2i1.13186

\begin{abstract}
In the present research we evaluated the effectiveness of the Laboratory Centers (L.C.) of the Technical and Vocational Secondary Schools in Athens, Greece in relation to the needs of the labor market, through teachers' and graduates' point of views. The research method followed was quantitative and concerned the L.C. that are subject to the Athens Secondary Education Administration. The findings of the research reveal that the curricula that are implemented by the L.C. are effective, as they meet the needs of the labor market, but they also highlight significant problems related to the lack of connection between the Greek L.C. and the local society and labor market as well as problems related to the laboratory infrastructures and to the teachers' training needs. The originality of the present study lies in the participation of L.C. graduates, who contributed to the revelation of the main obstacles that arise in the
\end{abstract}




\section{IIMacrothink}

Human Resource Research

ISSN 1948-5441

2018, Vol. 2, No. 1

relationship between the educational process and the real educational needs.

Keywords: Laboratory Centers, educational evaluation, effectiveness, labor market, local society, Technical Vocational Training Schools

\section{Introduction}

Laboratory Centers (L.C.) appear for the first time in Law 1566/1985 of the Greek Constitution and are called School Laboratory Centers. Their aim, as described in their founding law, is the practical training of students of technical-vocational senior high schools through their occupation with practical exercises.

Nowadays, in the Technical and Vocational Senior Secondary Schools of the country, the following sectors exist in the second grade and specializations in the third grade, according to the Government Gazette 1489/2016:

\section{SECTORS:}

(1) Sector of Agriculture, Food and the Environment

(2) Administration and Economy

(3) Section of Structural Engineering, Structured Environment and Architecture Designing

(4) Applied Arts

(5) Department of Electrical Engineering, Electronics and Automation

(6) Department of Mechanical Engineering

(7) Sectors of Maritime Occupations

(8) Computer Science

(9) Health - Social Welfare Sector

SPECIALTIES:

(1) Plant Production Technician

(2) Animal Production Technician

(3) Food and Beverage Technology Technician

(4) Florist and Landscape Architect

(5) Administration and Financial Services Officer

(6) Tourism Business Employee

(7) Marketing and Advertising Employee

(8) Warehouse and Supply Systems Employee

(9) Structural Engineer and Geoinformatics

(10) Graphic Arts

(11) Silverware

(12) Maintenance of Works of Art - Rehabilitation

(13) Design and Production of Clothing

(14) Designing - Interior Decorating

(15) Furnishing - Wood Sculpture 


\section{Macrothink}

(16) Technician of Electronic and Computational Systems, Installations, Networks and Telecommunications

(17) Technician of Electrical Systems, Installations and Networks

(18) Automation technician

(19) Mechanical Engineering and Construction Engineer

(20) Technician of Thermal and Hydraulic Installations and Technology Oil and Natural Gas

(21) Ventilation and Air Conditioning Cooling Technician

(22) Vehicle Technician

(23) Aerial Mechanic Engineer

(24) Merchant Marine Commander

(25) Merchant Marine Engineer

(26) IT Applications Technician

(27) Computer Engineer and Computer Networks

(28) Assistant Nurse

(29) Assistant of Medical - Biological Laboratories

(30) Assistant of Nursery School

(31) Assistant Physiotherapist

(32) Assistant Dental technician

(33) Assistant of Radiology Laboratories

(34) Pharmacy Assistant

(35) Aesthetic Art

(36) Hairdressing Art

The above Sectors and specialties are supported by the following 114 Laboratory Centers of the country as provided by the Governmental Gazette 1318/1-7-2015.

1. 0101 Mechanical Installations and Constructions

2. 0102 Thermal Installations and Technology of Oil and Natural Gas

3. 0103 Air Conditioning Installations

4. 0104 Vehicles

5. 0105 Aircraft

6. 0201 Electronic Applications

7. 0202 Telecommunication Systems

8. 0203 Electronic Computer Systems and Networks

9. 0204 Electrical Engineering

10. 0205 Automation

11. 0206 Electrical Installations

12. 0207 Electrical Car System

13. 0301 Building Projects 


\section{Macrothink}

14. 0302 Design Lab

15. 0401 Graphic Arts

16. 0402 Interior Design

170403 Maintenance of Artworks

18. 0404 Silversmiths

19. 0405 Printing and Staining

20. 0501 Technology - Production of Ready-Made Clothing

21. 0502 Furniture - Wood Carving

22. 0601 Agronomic and Environmental Aspects

23. 0602 Business Agriculture

24. 0603 Food and Beverage Technology

25. 0701 Aesthetic Art

26. 0702 Hairdressing

27. 0801 Medical - Biological - Pharmaceutical

28. 0802 Dental Technician

29. 0803 Nursing

30. 0804 Physiotherapy

31. 0805 Nursery School

32. 0806 Radiological

33. 0807 Chemical Laboratory Applications

340901 Merchant Naval Captain

35. 1001 Merchant Navy Engineers

36. 1101 Information Technology

37. 1102 IT Applications

38. 1201 Economy and Administration

Therefore, the purpose of the present study is basically to answer the following research questions:

1) Is the existing L.C. infrastructure and the management of its financial resources compatible with the needs of the labor market?

2) Can the educational staff of the L.C., through the educational process, meet the needs of the professional role for which it prepares students?

3) What form should the collaboration between the L.C. and the units of the labor market have?

Teachers and graduates from the L.C. have been the target group of the survey and have revealed valuable findings, while at the same time providing the community with valuable insights on the matter. 


\section{Literature Review}

Education according to Kehayas (2012) "is a set of elements that are linked to each other by interactive relationships and constitute a unit that is part of the broader system of society in which it operates" (p. 89). As a result, an "open" towards the local community school can listen to the real educational and working needs in the context of a creative interaction with the society, and, thus, adapt, change, help, and offer accordingly. According to Damanaki, Koulaidis, Kokkos, Lamnias and Dimopoulos (2006), an important part of the substantial operational responsibility is entrusted to the social forces -students, teachers, parents, local government, local production- involved in its operation.

In most European countries, technical education is linked to the labor market in several ways and mainly through internships (Wollschlager \& Reuter-Kumpmann, 2004). In Virginia, USA, the main pillar of technical education is "Work-based learning" (Richmond, 2014) and the educational system combines, in seven different ways, classroom teaching with work experience. The seven different ways have to do with the level of cooperation, which can be from simply employees informing students about their profession to working with a business to prepare a student for a particular job.

In the Vlassopoulos survey (2015), in which teachers, students and graduates of Technical Vocational Schools participated, it is clear that L.C. have quite good infrastructure, but teachers are dissatisfied with the reduced financing for buying consumables, due to the socio-economic crisis prevailing in Greece, which results in the non-application of many laboratory exercises. Also, in a recent study of Pavlou's (2016), students consider the building and laboratory infrastructure of their schools as adequate. They believe that laboratories play the most important role in their education and should get even better.

Teachers who teach at the L.C., as indicated by the specializations mentioned above, come from many disciplines and specialties, apart from the pedagogical dimension of their role, must also convey knowledge, know-how and skills related to their specialty. Factors such as inadequate infrastructure, scarce resources, and insufficient training place restrictions on their work and make them less effective (Matsaggouras, 2014).

Regarding teacher education by the State, Mavrogiorgos (1999) states that "it is a strategically important institution that offers the continuous and dynamic redefinition of the teachers' relationship with their work, personal, academic and professional development and evolution" (p.95). Unfortunately, as it can be observed in Daskagiannis (2010) research in the Attica region, $71 \%$ of teachers believe that their training is necessary to meet their educational needs and $81 \%$ would like the Ministry of Education and its stakeholders to carry out this training. However, $90 \%$ of L.C. teachers declared that both the Ministry of Education and the Attica Region Directorates are not interested in their educational needs. In a survey conducted by the Pedagogical Institute, $57 \%$ of teachers reported the lack of time as a major problem for their participation in training programs, while $75 \%$ declared that an important facilitation would be the exemption from their teaching duties during the training.

Regarding the needs of the market, as Brand, Valent, and Browning (2013) argue, today's levels of technology and the structure of the economy require better trained workforce than ever before, with more complex knowledge and skills compared to the demands of past 
professions. However, Akkerman and Bakker (2012, as reported by Magnus Fjellström \& Per Kristmansson, 2016) argue that it is doubtful if the knowledge acquired at school is useful in later work life, while knowledge developed in the workplace is directly related to the needs of work.

In a related research of the Pedagogical Institute (2008) it has been found that the content of the school books -despite the revisions- does not keep pace with the developments in the field of science because, as it is pointed out, all the attempts to reform the Curricula that have taken place in Greece are centralized, fragmented and inadequate because valid criteria have not been met. Also, in the same survey Technical and Vocational School teachers report that today's school responds only by $49 \%$ regarding their expectations by the content of the school curricula.

It is a central trend in the world that quality in education is linked to evaluation and, as Casamia notes (2007, as reported in Koutouzis, 2008), it is "a need to improve the quality, effectiveness and efficiency of educational systems with a key criterion the result". Even in recent years, it is also seen as a social requirement. Assessing the effectiveness of an educational system or school unit is an important tool for assessing and improving the quality of the education provided (Loukopoulos, 2013).

An important dimension of quality is effectiveness, which is defined as the achievement of the objectives set by Vocational Education Curriculum (Pilar Pineda-Herrero, Carla Quesada-Pallarès, Berta Espona-Barcons, \& Oscar Mas-Torelló, 2015). Besides, the definition of quality in education itself is a difficult process, since it can mean different things in different contexts, for those involved in the educational process, for educators and for education policy makers (Elassy, 2015).

In technical education, for example, we meet teachers who perform excellent teachings in a flawless educational environment but which do not meet the needs of the trainees and of the profession they teach (Shaidullina et al., 2015), for many different reasons, either because the knowledge and skills taught are outdated or because they are unable to link theory to practice or even the existing infrastructure is inappropriate and insufficient. These teachers are considered as effective for the internal operation of the school unit but ineffective in terms of the overall goal of the school unit.

\section{Methodology}

\subsection{The Method}

In the survey we conducted for the evaluation of L.C. we followed a quantitative approach through a survey. The sample survey is appropriate according to Creswell (2008), to describe the relationships between variables, but also to identify the individual views, attitudes and practices of the target population of research. In the present research, variables have been associated, for example, with the funding of the L.C., with their responsiveness to the labor market, with the attitudes, views and practices of the target population, the relationship and cooperation of the L.C. with local society and the labor market, with teacher education, with the analytical curricula and the lab infrastructure. As a "unit of analysis", at the level of data collection, the Directorate of Secondary Education of Athens' 1st sub-region was chosen. 


\section{Macrothink}

It was decided to assign the responsibility for the delivery and receipt of the questionnaires filled in by the teachers, to the L.C. Directors, given that the relationship supervisor-employee will provide the researcher with better return rates. In the survey participated all the teachers (lab coordinators) of the seven L.C. of Athens' 1st sub-region, thus nullifying the sampling error. Eventually, eighty questionnaires were collected. In the case of students who have graduated from the above L.C. and are working in their specialty and for whom the L.C. did not have data, the sample without probability was chosen, that is, a convenient sample indicated by the directors and the L.C. teachers. This sample consisted of 30 employees.

All questionnaire questions are closed-ended and for several answers the Likert scale was used with a five-stage rating: 1) not at all 2) a little 3) quite enough 4) a lot 5) very much. The Likert scale uses fixed responses and is designed to measure attitudes and views (Rattray \& Jones, 2007). The SPSS 16 statistical program was used for data processing by applying descriptive and inductive statistical analysis.

\subsection{The Sample}

Of the 80 teachers who responded to the questionnaire, 51 were male $(63.8 \%)$ and 29 women $(36.2 \%)$. The average of the educational experience of the 80 teachers who completed the questionnaire is 21.80 years, while the dominant value is 17 years and refers to 9 teachers (11.2\%). Out of the 80 teachers who completed the questionnaire, $39(48.8 \%)$ also teach the corresponding theoretical lesson that is the base for the laboratory, while 41 (51.2\%) do not teach the corresponding theoretical lesson.

Out of the 30 respondents to the questionnaire, 21 were male and 9 were female, which represents the $70 \%$ and $30 \%$ respectively. The average age of the employees was 26.7 years. To the question about whether the diploma from the Secondary Technical and Vocational School was a necessary qualification for their work, $70 \%$ answered yes and $30 \%$ did not answer. The average work experience of the respondents was 4.4 years. The dominant value in relation to the year of graduation from the Technical and Vocational School was the year 2012 while the median year was 2013.

\section{Findings}

\subsection{Laboratory Infrastructure}

The findings of the survey revealed that $56.2 \%$ of the L.C. teachers who completed the questionnaire believe that the standards of their laboratory equipment are proportional to the needs of the Analytic Curricula while $30 \%$ believe that it is proportional to the available resources and $13.8 \%$ consider that it is proportional to the needs of the labor market.

$46.2 \%$ of the teachers stated that the school committee covered their needs in consumables from $80 \%$ to $100 \%$, while the $16.2 \%$ stated that the school committee covered up to $20 \%$ of their needs. $32.4 \%$ of teachers declared that the total funding of their laboratory per year was inadequate to moderate, $31.2 \%$ declared it was good, $28.8 \%$ very good and $7.5 \%$ more than enough.

$58.7 \%$ of the teachers reported that the renewal of the lab equipment in their laboratories after their founding has been accomplished at a level of up to $40 \%$, while $18.8 \%$ of the teachers 
reported a rate of renewal of $60 \%$ to $80 \%$ and $6.2 \%$ of the teachers reported a renewal from $80 \%$ to $100 \%$.

$43.7 \%$ of the teachers stated that their laboratory equipment meets the requirements of the Analytical Curriculum up to $60 \%, 25 \%$ of the teachers reported coverage from $60 \%$ to $80 \%$ and $31.2 \%$ of the teachers from $80 \%$ to $100 \% .63 .8 \%$ of teachers stated that the infrastructure of their lab is more or less identical with the corresponding one in the labor market, $25 \%$ of teachers reported it is a lot identical and $7.5 \%$ quite a lot.

$83.8 \%$ of the teachers declared that their lab does not meet the labor market needs, while $16.2 \%$ declared that it responds to the market needs. The results of the statistic test showed that the laboratory's response to the labor market needs is related to its total funding $(\mathrm{p}=$ $0.008<0.05$ ). $57.5 \%$ of teachers stated that the renewal of the laboratory equipment should be done every 5 years, so that the lab can meet the needs of the labor market, while the $37.5 \%$ stated every 10 years and the $5 \%$ of them every 15 years.

Regarding the answers of the graduates, $56.7 \%$ of respondents stated that the infrastructure of the laboratories of the school from which they graduated covered the needs of their work little to enough, $33.3 \%$ stated a lot, and $10 \%$ of the graduates stated very much. $63.3 \%$ of the respondents stated that the specifications of the equipment of the laboratories are proportional to the needs of the labor market, compared to the $36.7 \%$ who disagreed.

$50 \%$ of the respondents stated that the materials that they used in their laboratory lessons were from little same to same enough compared to the ones they find today in their workplace. $46.7 \%$ of the respondents stated that the materials used in the laboratory was from much to very much the same with the ones used in their workplace. $36.7 \%$ of the respondents considers the material infrastructure of the laboratories much to very much outdated, the $23,3 \%$ considers it as outdated enough, the $33,3 \%$ a little outdated and the $6,7 \%$ not at all outdated.

$40 \%$ of the respondents replied that, in order to allow laboratories to meet the needs of the labor market, equipment renewal should be accomplished every five years, 30\% replied that it should be accomplished every decade, $20 \%$ every fifteen years, and $10 \%$ every 20 years.

\subsection{Teachers' Training}

$76.3 \%$ of teachers stated that their continuing education is from much to very much necessary to be effective in their duties, $18.8 \%$ of the teachers stated it is quite necessary and $5 \%$ of them a little necessary or not at all.

$90 \%$ of the teachers declared they were little or not at all satisfied with the frequency of seminars organized by the Ministry of Education, while 10\% declared from satisfied enough to much satisfied. $16.2 \%$ of the teachers attended training on the subject they teach 1 year ago, $26.2 \% 3$ years ago, $22.5 \% 5$ years ago, $25 \% 7$ years ago and $10 \%$ more than 7 years ago.

$72.5 \%$ of the teachers declared that the in-school training was effective against the $27.5 \%$ who declared that it wasn't. $81.3 \%$ of teachers stated that the organization of training programs by people of the labor market for the enhancement of their professional competence is from much to very much needed, while $18.7 \%$ stated that it is a little to quite a lot needed.

$50 \%$ of the teachers declared that they have to attend training programs to keep up with technology progress every year, $28.8 \%$ declared every 3 years, 15\% every 5 years and 5\% 
every 7 years. $63.8 \%$ of the teachers declared that they have been facilitated by their supervisors every time they wanted to attend training programs, $30 \%$ declared sometimes and $6.2 \%$ not at all.

$91.2 \%$ of the teachers stated that they are following the self-learning process to track the progress of technology in their specialization, compared to the the $8.8 \%$ who responded negatively. $70 \%$ of teachers stated that they perceived themselves as little to fairly aware of the real labor market needs of their specialty and 30\% declared very much aware.

\subsection{Graduates' and Teachers' Developed Skills}

$46.6 \%$ of the respondents said that lab teachers taught them little to quite enough skills that helped them in their later work life, compared to the $46.7 \%$ who declared much and $6.7 \%$ who declared very much.

$53.3 \%$ of the respondents consider that the teachers of the laboratory courses are little to quite enough informed about the needs of the labor market, compared to the $43.4 \%$ who consider them to be very much informed.

$53.3 \%$ of the respondents very much believe that lab teachers should be in constant contact and constantly informed by people in the labor market. $33.3 \%$ believe it much, $13.3 \%$ quite enough and $0 \%$ of the respondents believes little or not at all.

$100 \%$ of the respondents considers work experience on their specialty as necessary quality for the teachers of the laboratories.

\subsection{Analytical Curricula}

1-3 years ago, the majority of the Curricula of the specialty courses taught by the teachers of the sample has changed with a dominant value of 2 years at a percentage of $31.2 \%$, followed by 1 year ago at a percentage of $28.8 \%$ and the 3 years ago at $12.5 \%$.

$45 \%$ of teachers stated that the changes in the Curricula do not take at all into account the existing hardware and software infrastructure of schools, $50 \%$ stated sometimes and 5\% stated always.

$58.8 \%$ of the teachers responded that the content of the Curricula develops knowledge and skills that can be applied to real working conditions while $41.2 \%$ responded negatively.

$73.8 \%$ of the respondents did not observe an effort to reduce the volume of material to be taught during the change of the Curricula, in order for the teachers to be able to focus on the actual and essential needs of the profession, while $26.2 \%$ responded positively.

$62 \%$ of the teachers surveyed believe that the content of the Curricula develops skills that can be matched with a specific work licensure, while $37.5 \%$ responded negatively.

$55 \%$ of the respondents answered that the Curricula allow them to spend between $10 \%$ and $20 \%$ of their teaching time, in order to develop topics outside the Curriculum, which are considered necessary to carry out the professional activity in the future. $31.2 \%$ responded that the Curricula leave no room for additional topics and $13.8 \%$ of the teachers that they leave $20 \%$ to $30 \%$ of the available teaching time.

$91.2 \%$ of the teachers responded that an institution should be founded, in order to continuously assess and renew the Curricula with a view to constantly adjust them to technological progress, while $8.8 \%$ of the teachers responded negatively. 
$87.5 \%$ of the teachers consider it necessary to participate in the evaluation of the Curricula, while $12.5 \%$ responded negatively.

\subsection{Laboratory Books}

$33.3 \%$ of the respondents rarely consult the laboratory books to get some information about their work, $60 \%$ often to many times and $0 \%$ constantly.

$50 \%$ of the respondents stated that several of the lab exercises included in their school books cover the needs of their work, compared to $30 \%$ responding much, $0 \%$ very much, $6 \%$ little and $0 \%$ not at all.

$56.7 \%$ of the respondents answered that there are several exercises in the laboratory books, the topics of which have long been outdated in the labor market, $33.3 \%$ answered few of the exercises and $10 \%$ answered none of them.

$43.3 \%$ of the respondents stated that the teachers of the laboratory courses taught them several exercises that are useful to their work but are not included in their books, 16.7 answered no exercises, $20 \%$ few exercises and $20 \%$ many.

$43.3 \%$ of the respondents declared that based on their work experience, the knowledge and skills that are gained from the exercises of the laboratory books correspond to the actual labor market conditions, compared with the $30 \%$ responding a little, $20 \%$ a lot and $3.3 \%$ not at all and very much.

$73.3 \%$ of the respondents replied that the teaching time was enough to complete the laboratory exercises of their books, compared to $26.7 \%$ who responded negatively. $73.3 \%$ of respondents replied that they had enough time to get deeper if in some exercises it was necessary, when $26.7 \%$ answered negatively.

\subsection{Connection with the Labor Market}

$71.2 \%$ of teachers responded that they do not cooperate with chambers, professional associations, employers' organizations and other productive and social actors in the region of the L.C., while the $28.8 \%$ responded positively.

$53.8 \%$ of teachers responded that they spend a little teaching time on topics related to the working needs of the local community, 26.2\% responded not at all and $20 \%$ responded enough time.

$81.2 \%$ of teachers responded that they organize visits to local production units, while $18.8 \%$ responded negatively.

$42.5 \%$ of teachers responded that they do not occupy students with activities such as constructions, projects, programs and students' internships in local production units, while $37.5 \%$ stated that they occupy them sometimes, and 20\% that they occupy them every school year.

$57.5 \%$ of teachers responded that they do not develop in their Laboratory Social Responsibility activities for the needs of the local community, while $31.2 \%$ answered sometimes and $11.2 \%$ never.

$46.2 \%$ of teachers believe that the legislative framework of the L.C. favors a little the cooperation with the labor market units, while $43.8 \%$ believes not at all and $10 \%$ quite enough. The result of the Chi-Square Test showed that the refusal of the responsible 


\section{MInstitute ${ }^{\text {Mink }}$}

laboratories to cooperate with chambers, professional associations, employers' organizations and other productive and social actors in the region of the L.C. is related to the legislative framework for the operation of the L.C. $(p=0.03<0.05)$.

$42.5 \%$ of teachers responded that the collaboration with the labor market is much helpful with the effectiveness of their teaching, $28.8 \%$ responded very much helpful, $21.2 \%$ helpful enough and $7.4 \%$ little to not at all helpful.

$36.7 \%$ of respondents stated that most of the exercises would be more effective if applied in workplaces, $33.3 \%$ answered many, $10 \%$ several, $16.7 \%$ few and $3.3 \%$ none. $93.3 \%$ of the respondents replied that they consider it necessary to cooperate with local production units, chambers, workers' associations, etc. in order to improve the efficiency of the educational process, compared to $6.7 \%$ who responded negatively.

$96.7 \%$ of respondents consider educational visits to production units effective, compared with $3.3 \%$ who are negative. $43.3 \%$ of the respondents said that the link between L.C. and the labor market is effective, compared to $33.3 \%$ responding that it is non-existent and $23.3 \%$ that described it as ineffective.

$73.4 \%$ of the respondents stated that the execution of laboratory exercises adapted to the working needs of the local community would have from little to much effect on their professional orientation, compared with the $26.7 \%$ who responded not at all.

$56.7 \%$ of the respondents responded based on their professional experience to date that students should have a working relationship with the workplace of their specialty with their entry to the school, $26.7 \%$ after the 1 st grade of the Senior Secondary Vocational school, $13.3 \%$ after 2 nd grade and $3.3 \%$ after 3 rd grade. $93.3 \%$ of the respondents replied that they would like to be able, within the framework of an institutionalized procedure, to submit proposals for improving the educational process of the L.C. of the region in which they live, compared with $6.7 \%$ who responded negatively.

\section{Discussion of the Results}

From the teachers' point of view, the L.C. are a bit similar to the respective labor market laboratories, and they do not meet the market needs since their overall funding is not satisfactory. While funding from school committees, particularly for consumable materials, is considered satisfactory, teachers are dissatisfied with the reduced financing of the market for consumable materials, due to the socio-economic situation prevailing in Greece, contrary to the results of Vlasopoulos' research (2015), in which it emerges that laboratories have a fairly good infrastructure. Interpreting the findings from the employees' replies, we find that the laboratory equipment is considered obsolete, does not meet the needs of the labor market and, because of deficiencies, teachers fail to perform several laboratory exercises.

From the teachers' point of view, we would say that EC teachers are mainly trying to train themselves, since their do not cover their training needs as frequently as they would like, confirming Daskayiannis' (2010) study, in which 90\% of L.C. teachers state that both the Ministry of Education and the Attica Region Directorates are not interested in their educational needs. They recognize that cooperation with people from the market is absolutely necessary in order to be effective, but they do not perceive themselves as aware of the actual needs of the labor market so that through the educational act they meet the requirements of 
the work-role for which they prepare their students. We also result in the same findings by interpreting the employees' replies, who state that many of the skills that helped them in their work were not taught during their studies. Moreover, only $43.4 \%$ of the teachers consider that are very well informed about the needs of the labor market. They consider the work experience of teachers to be necessary to teach laboratory lessons and at high rates they believe that lab teachers should be in constant contact and constantly informed by people from the labor market.

The Analytical Curricula of the Laboratories respond to the needs of the labor market although they contain some material that could be omitted. The research of the Pedagogical Institute (2008) confirms that the content of the school books despite the revisions is not in line with the developments in the field of science and knowledge. Employees themselves positively evaluate the Curricula in relation to the professional requirements of their specialty, since $80 \%$ of them believe that the content of the books meet their work needs and even $60 \%$ of them often consult the school books. Finally, they point out that there are exercises that have been obsolete for a long time for the labor market, and, even more, $76.7 \%$ declares that the teachers have taught these exercises.

Regarding the connection to the labor market, $71.3 \%$ of the teachers recognize that their labor market collaboration is very important because it contributes to the effectiveness of their teaching. However, a same percentage responds that they do not cooperate since they consider that the L.C. legislative framework does not favor cooperation with the labor market, confirming Zaheila's (2012) research on non-existent cooperation between the educational system and the labor market. Regarding the local community, they do not develop activities or dedicate teaching time to topics that have to do with the local community.

Employees at a percentage of $93.3 \%$ consider it as necessary for the L.C. to cooperate with local production units, chambers, workers' associations, in order to improve the efficiency of the educational process. $56,6 \%$ of the respondents reported that the link between the L.C. and the labor market was ineffective, confirming the research of the Center for the Development of Educational Policy (KANEP) of the General Association of Employees in Greece (GSEE) and the University of Crete that took place in 2013 and underlined that $16.9 \%$ of young people up to 24 years old (Greece) are out of the labor market, education or training, and the overwhelming majority (regardless of their level of education) considers education to be totally ineffective in relation to the connection with the labor market. They also consider that many laboratory exercises would be more effective if executed at workplaces, confirming the view of Akkerman and Bakker (2012, as reported by Magnus Fjellström \& Per Kristmansson, 2016) who argue that it is doubtful if the knowledge gained in school is useful for later working life, while the knowledge that is gained in the workplace directly relates to the needs of the job. Employees also believe that the students of the Senior Secondary Technical and Vocational School should have a working relationship with the workplace upon entering the School, through work-based learning systems (Richmond, 2014). They further believe that the execution of laboratory exercises adapted to the working needs of the local community would affect their professional orientation. Finally, 93.3\% of the employees would want, through an institutionalized process, to submit proposals for improving the educational process of the L.C. of their region, confirming the KANEP-GSEE report (2017) which states 
that the local community should play an active role in highlighting the weaknesses and shortcomings of the educational system and actively participate in the formulation of the educational policy.

\section{Limitations and Suggestions for Future Research}

The present study focused on evaluating the efficiency of the Laboratories in the Technical and Vocational Secondary Schools of the 1st sub-region of Athens in Greece, through the valuable participation of teachers and graduates. In the future, researchers could also focus in more regions of Athens and the Periphery, in order to gain further valuable insights and affect the decisions of policy-makers.

\section{Conclusions}

The present research revealed practices and ideas that concern all those involved in the educational process of the L.C. -the State, the local government, the labor market, the local community and the technical school units- which, if utilized appropriately, will contribute to adapting the educational needs to the actual needs of the labor market, thus improving their effectiveness. Furthermore, it is clear that L.C. can, and should, as autonomous schools, pave the way of the Technical and Vocational Secondary Education Schools for a meaningful connection of the vocational education and training of our country with the labor market.

\section{References}

Brand, B., Valent, A., \& Browning, A. (2013). How career and technical education can help students be college and career ready: A Primer. College and Career Readiness and Success Center.

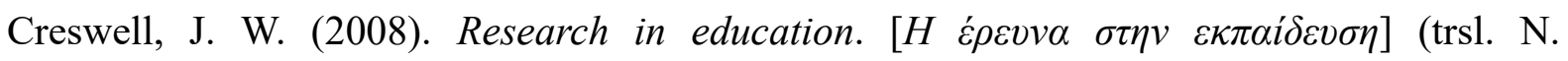
Kouvarakou). Athens: Ion

Damanaki, M., Koulaidis, V., Kokkos, A., Lamnias, K., \& Dimopoulos, K. (2006). An open to

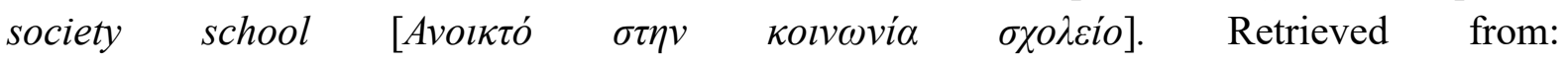
https://eparemvasiax.files.wordpress.com/2009/10/anoikto-sxoleio-pasok-mardamanaki.pdf

Daskayianni, A. (2010). Investigation of the training needs of the management employees of the School Laboratory Centers in managerial and economy topics: The example of

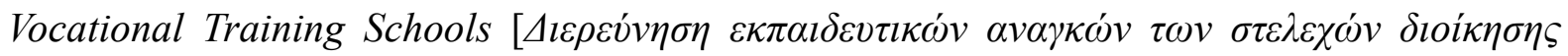

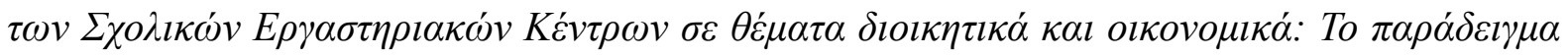

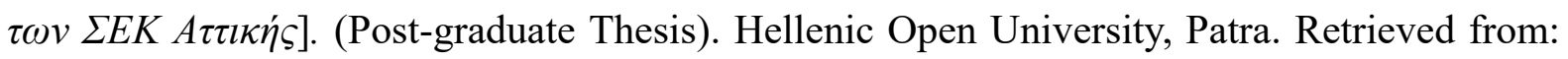
https://apothesis.eap.gr/handle/repo/19307

KANEP-GSEE. (2017). The basic aspects of education 2016. The Greek primary and

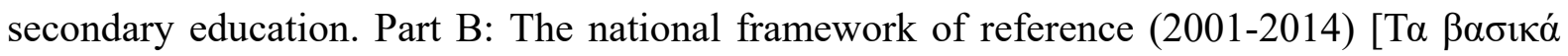

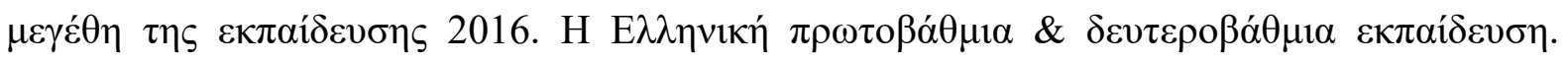

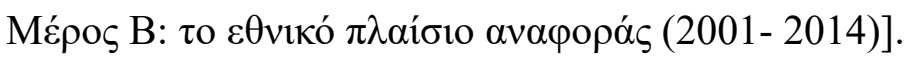

Kehayas, S. (2012 July - December). School unit, local community and local authorities

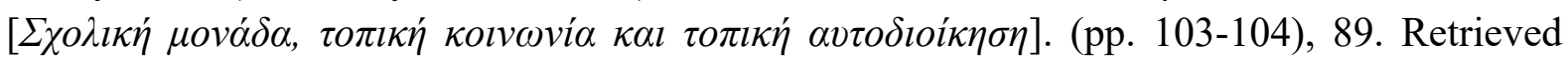
from http://www.taekpaideutika.gr/ekp_103-104/periexomena_103-104.pdf

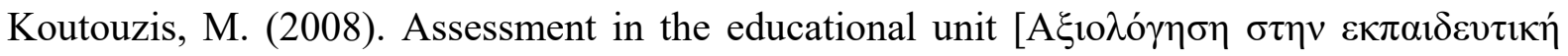

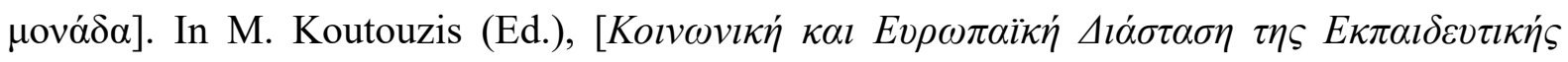




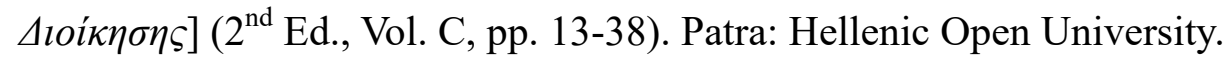

Loukopoulos, A. (2013). Evaluation of the effectiveness of the new educational material of

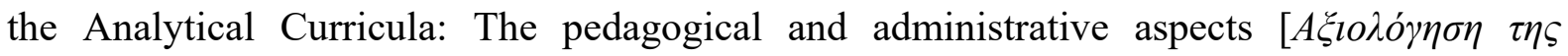

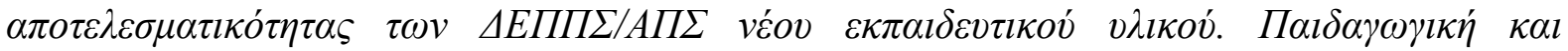
$\delta \imath \alpha \chi \varepsilon \iota \rho \imath \sigma \tau \imath \kappa \eta ́ ~ \delta \imath \alpha ́ \sigma \tau \alpha \sigma \eta]$ (Doctoral Thesis). University of Patra. Retrieved from: http://www.didaktorika.gr/eadd/handle/10442/29119

Magnus Fjellström \& Per Kristmansson, (2016) "Learning as an apprentice in Sweden: A comparative study on affordances for vocational learning in school and work life apprentice education", Education + Training, 58(6), 629-642, doi: 10.1108/ET-12-2015-0113

Matsaggouras, E. (2014). Introduction to the theoretical principles, the procedures and the tools of the evaluation system. Preliminary actions for the application of the evaluation system of the training material for the assessment of the employees and the teachers of the

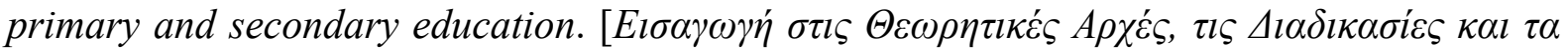

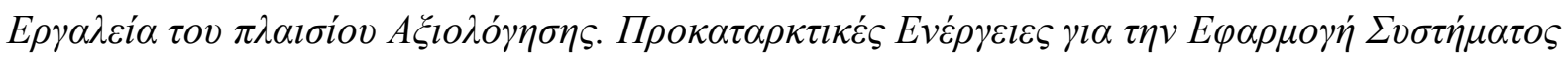

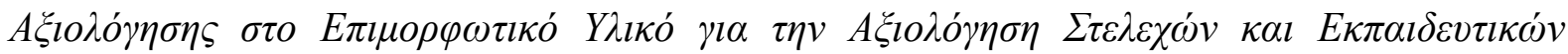

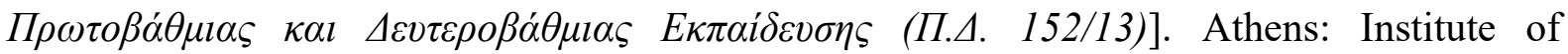
Educational Policy. Retrieved from: http://users.sch.gr/klouvatos/AEE/EPIMORFOTIKO\%20YLIKO_AXIOLOGISI_TELIKO_ CD.pdf

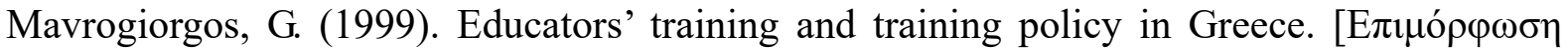

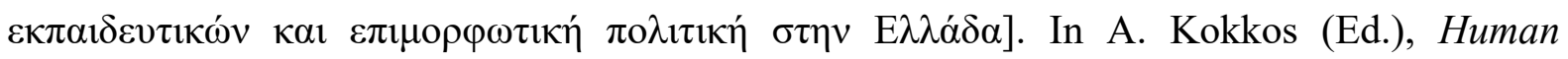
Resources Management (pp. 93-135). Patra: Hellenic Open University.

Elassy, N. (2015) "The concepts of quality, quality assurance and quality enhancement", Quality Assurance in Education, 23(3), 250-261, doi: 10.1108/QAE-11-2012-0046

Pavlou, Ch. (2016). Students of the Technical and Vocational Secondary Schools and school

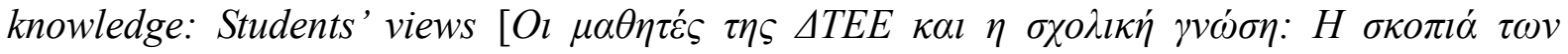
$M \alpha \theta \eta \tau \omega \dot{v}]$. (Doctoral Thesis, University of Peloponnese). Retrieved from: https://www.didaktorika.gr/eadd/handle/10442/37774

Pedagogical Institute (2008). Quality in Education. Research for the Evaluation of the

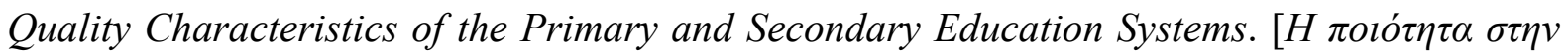

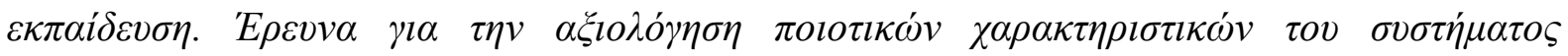
$\pi \rho \omega \tau о \beta \alpha ́ \theta \mu l \alpha \varsigma \quad \kappa \alpha l \quad \delta \varepsilon v \tau \varepsilon \rho о \beta \alpha \dot{\theta} \mu l \alpha \varsigma \quad \varepsilon \kappa \pi \alpha i \delta \varepsilon v \sigma \eta \varsigma] . \quad$ Retrieved $\quad$ from: http://www.pi-schools.gr/programs/erevnes/index_axiol.php

Pilar Pineda-Herrero, Carla Quesada-Pallarès, Berta Espona-Barcons \& Óscar Mas-Torelló, (2015) "How to measure the efficacy of VET workplace learning: the FET-WL model", Education Training, 57(6), 602-622, doi: 10.1108/ET-12-2013-0141

Rattray, J., \& Jones, M. C. (2007). Essential elements of questionnaire design and development. Journal of clinical nursing, 16(2), 234-243.

Richmond, V. (2014). Career and Technical Education Work-Based Learning Guide.

Shaidullina, A. R., Sinitzyn, O. V., Nabiyeva, A. R., Yakovlev, S. A., Maksimov, I. N., Gatina, A. R., \& Akhmetov, L. G. (2015). Functions and Main Directions of Development of the Integrated Educational-Industrial Complex "College-University-Enterprise". Review of 


\section{Macrothink}

Human Resource Research

ISSN 1948-5441 2018, Vol. 2, No. 1

European Studies, 7(4), 228. doi: http://dx.doi.org/10.5539/res.v7n4p228

Vlassopoulos, G. (2015). Investigation of the quality of education in public technical and vocational schools and its correlation with modern socio-economic reality [ $\Delta \imath \varepsilon \rho \varepsilon v v v \eta \sigma \eta \tau \eta \varsigma$

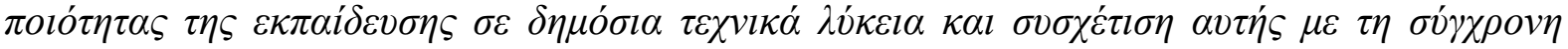

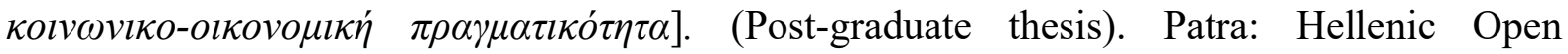
University. Retrieved from https://apothesis.eap.gr

Wollschlager, N., \& Reuter-Kumpmann, H. (2004). From Divergence to Convergence: A History of Vocational Education and Training in Europe. European Journal: Vocational Training, 32, 6-17.

Zaheilas, L. (2012). The effect of the National Framework of Qualifications on the educational and training systems and on the enhancement of their relationship with the labor

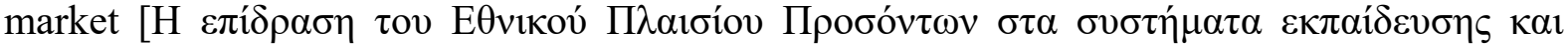

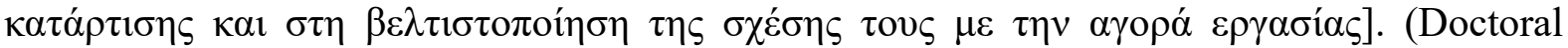
thesis). University of Sterea Ellada. Retrieved from: https://www.didaktorika.gr/eadd/handle/10442/29958

\section{Copyright Disclaimer}

Copyright for this article is retained by the author(s), with first publication rights granted to the journal.

This is an open-access article distributed under the terms and conditions of the Creative Commons Attribution license (http://creativecommons.org/licenses/by/3.0/). 